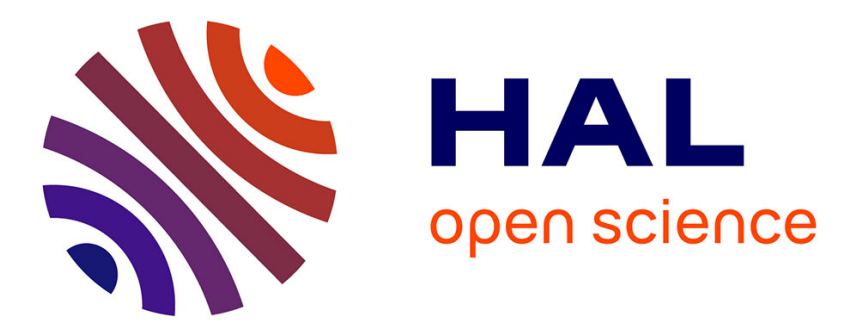

\title{
Virtual Scuba Diving System Utilizing the Sense of Weightlessness Underwater
}

Kazuma Nagata, Denik Hatsushika, Yuki Hashimoto

\section{To cite this version:}

Kazuma Nagata, Denik Hatsushika, Yuki Hashimoto. Virtual Scuba Diving System Utilizing the Sense of Weightlessness Underwater. 16th International Conference on Entertainment Computing (ICEC), Sep 2017, Tsukuba City, Japan. pp.205-210, 10.1007/978-3-319-66715-7_22 . hal-01771246

\section{HAL Id: hal-01771246 \\ https://hal.inria.fr/hal-01771246}

Submitted on 19 Apr 2018

HAL is a multi-disciplinary open access archive for the deposit and dissemination of scientific research documents, whether they are published or not. The documents may come from teaching and research institutions in France or abroad, or from public or private research centers.
L'archive ouverte pluridisciplinaire HAL, est destinée au dépôt et à la diffusion de documents scientifiques de niveau recherche, publiés ou non, émanant des établissements d'enseignement et de recherche français ou étrangers, des laboratoires publics ou privés.

\section{(c)(1)}

Distributed under a Creative Commons Attribution| 4.0 International License 


\title{
Virtual Scuba Diving System Utilizing the Sense of Weightlessness Underwater
}

\author{
Kazuma NAGATA $^{1 *}$, Denik HATSUSHIKA ${ }^{2}$ and Yuki HASHIMOTO \\ 1,2,3 University of Tsukuba, 1-1-1 Tennodai Tsukuba Ibaraki 305-8573, Japan \\ ${ }^{1}$ nagata.kazuma@entcomp.esys.tsukuba.ac.jp \\ 2 d hatsushika@vrlab.esys.tsukuba.ac.jp \\ ${ }^{3}$ hashimotodit.tsukuba.ac.jp
}

\begin{abstract}
We propose a virtual scuba diving system using an underwater head mounted display (UHMD). This system has two advantages. First, a strong sense of reality is obtained by combining the weightlessness obtained by diving with a highly immersive image presented by a waterproof UHMD. Second, the system is very versatile, such that a user can experience the system in easily accessible waters such as swimming pools or shallow water. In this paper, we describe the design and implementation of the proposed system and the creation of underwater virtual reality (VR) content to provide a diving experience. The proposed system consists of the UHMD with a head tracking sensor, laptop PC, and a hose to protect the cables. The UHMD and laptop PC are connected by cables for power, communication, and video transmission. Each part is waterproof. The created VR content makes it possible to freely swim in the virtual undersea world by head tracking and operation of the controller. We conducted a pilot experiment to test the proposed system while users swam in a pool of about $4 \mathrm{~m}$ in depth. The UHMD was confirmed to have sufficient waterproofness at water depth of about $4 \mathrm{~m}$. It is also suggested that it is possible to create the illusion that the water depth in the virtual underwater space is the user's own water depth.
\end{abstract}

Keywords: Scuba Diving, Head Mounted Display, Underwater, Virtual Reality

\section{Introduction}

Scuba diving is an attractive sport that enables participants to enjoy a mysterious and beautiful underwater world. However, scuba diving cannot be enjoyed easily anytime. A license is required for free diving, and there is a limit to the depth of dives for safety. In addition, it is necessary to consider the appropriate location, time, and weather to do scuba diving.

Our goal is to realize a virtual scuba diving system so that anyone can enjoy a diving experience with high reality at any time in familiar waters such as pools.

Many systems to experience the underwater virtually have been proposed [1-4]. However, many of them present underwater images while the user is not in the water. Therefore, it is difficult for these systems to present weightlessness and water resistance. In 
contrast, several virtual underwater experience systems in which the user is underwater have been proposed in recent years. DOLPHYN [5] is an underwater experience system equipped with sensors such as a webcam, GPS, thermometer, flowmeter, and tablet PC. Users can experience the virtual undersea world through the DOLPHYN display. However, this system has less immersion than a head mounted display (HMD). In addition, body movement is restricted because it is necessary to operate the equipment with both hands. AquaCAVE [6,7] realizes the experience of swimming in the ocean by projecting images on the wall of the aquarium. However, the available places for experiencing this system are limited because of the necessity of preparing a dedicated aquarium. The movement of the user is also limited by the narrowness of the aquarium.

Hence, this research proposes a new virtual underwater experience system using an underwater HMD (UHMD). Several UHMDs have been proposed [8-10]. These systems use a smartphone with a waterproof case, and users can enjoy a virtual sea world synchronized with the movement of their head underwater. However, because of the limitations of smartphone performance, the quality of the computer graphics (CG) that can be provided is not high. Moreover, there is a possibility of virtual reality (VR) sickness due to insufficient head tracking performance. Furthermore, the feeling of immersion is lower than with a dedicated HMD. In contrast, we aim to design and implement a system to solve this problem.

In this paper, we report on the design and implementation of our system, its content production, and the result of a verification of the system's operation in a pool.

\section{System Configuration}

\subsection{Design Principle}

Our system is designed to be used at a depth of about $4 \mathrm{~m}$, in which the whole body of a person can move freely in the water. For this reason, we decided to make the system waterproof enough to withstand a water depth of $4 \mathrm{~m}$. According to Oculus best practices [11], we tried to render CG at $75 \mathrm{fps}$ or higher, and selected a sensor so that the tracking delay would be less than $20 \mathrm{~ms}$. To address portability, we decided to design the system to a weight and size that can be carried by one person.

\subsection{Implementation}

Our system consists of a UHMD with head tracking sensor, laptop PC, and a hose that protects cables. The UHMD and laptop PC are connected by cables for power, communication, and video transmission. The use of a laptop increases the system portability. The UHMD system is shown in Fig. 1. 


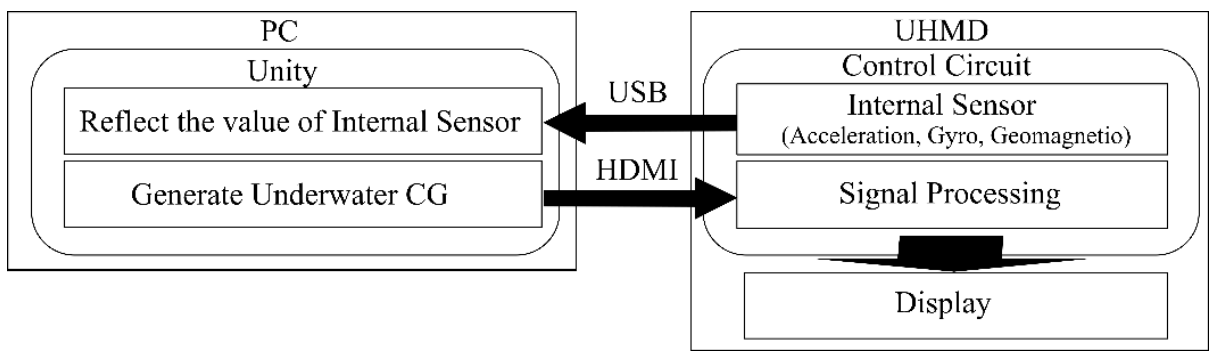

Fig. 1. Configuration of the UHMD system.

For the UHMD body, we disassembled an Oculus Rift DK 2 (Oculus VR, Inc.) and used the circuits and display. The cables were $10 \mathrm{~m}$ in length so that the system could move freely at a water depth of $4 \mathrm{~m}$. For head tracking, the internal sensor of Oculus Rift DK 2 was used. The laptop GPU (NVIDIA, Geforce GTX 980M) was used for video output.

The UHMD was entirely covered with a circuit sealing agent. The connector was protected with a waterproof-type heat shrink tube. Hose was used to protect the wired cables. Further, to ensure close contact between the user and the UHMD, the frame of an underwater mask was joined with the HMD section (Fig. 2). We applied defogging liquid to the HMD's lenses.

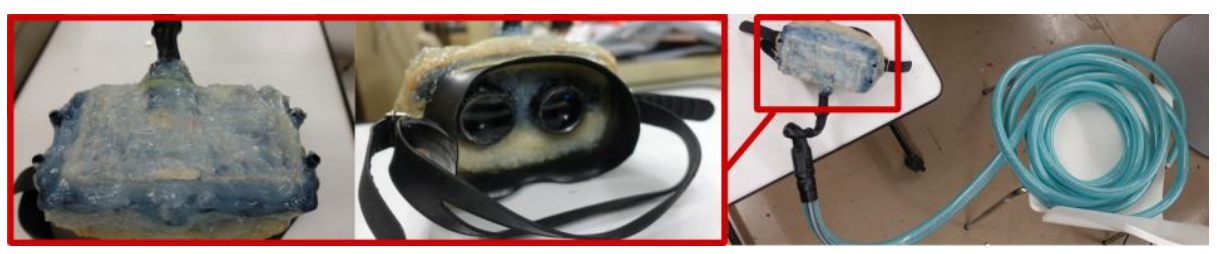

Fig. 2. Image of the UHMD.

\section{Production of Content}

\subsection{Scene Design}

We produced underwater content using Unity, which can create high-quality CG and is easy to link with external equipment. To achieve a good VR experience, we adjusted the number of 3D objects and effects so that the frame rate did not fall below $75 \mathrm{fps}$. We produced two diving environments. One is a shoal (Fig. 3, left). The depth of this scene is $5 \mathrm{~m}$. The user can watch seaweed, coral, and a school of fish. The other virtual environment is large vertical hole (Fig. 3, right). The depth and diameter of this scene is $40 \mathrm{~m}$. The surroundings become darker as the water depth increases. To make the surroundings visible, even in deep water, we installed a light that illuminates the field of vision on the head of the user. The user can see various types of seaweed, various corals, and two whales. 

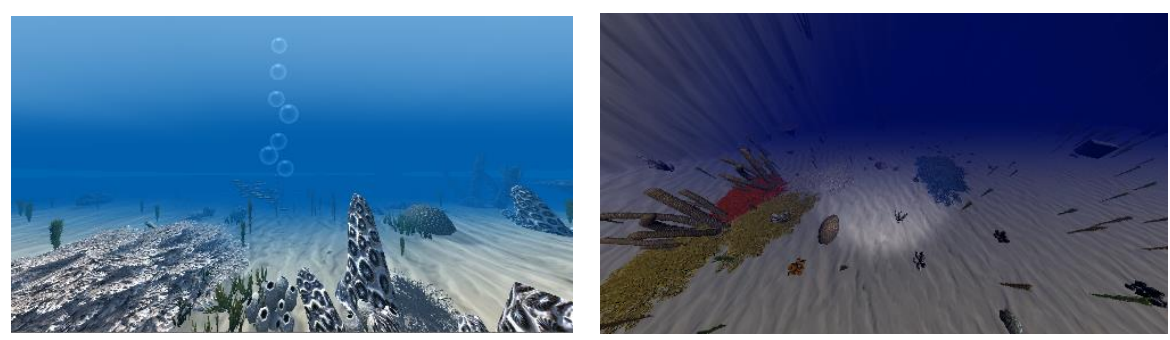

Fig. 3. Left: shallow water. Right: vertical hole

\subsection{Interaction Design}

The movement of the user's head is recognized by the sensor for tracking and fed back to the visual field of the CG in real time. A controller is used to move the user. The joystick is used to move in the planar direction, the trigger is used to change the depth, and buttons provide instantaneous movement to preset locations.

\section{$4 \quad$ Pilot Study}

\subsection{Content of the Pilot Study}

We conducted a pilot study using our system in an indoor pool (maximum water depth of $3.8 \mathrm{~m}$ ) to confirm that the system operates normally in water and determine the immersion obtained by this system. In this study, participants dived completely into the water and looked around for as long as they could hold their breath (Fig. 4). Our system followed the rotation of the head, but could not acquire other movement. We instructed the participants not to move during diving and they did not use a controller. The vertical hole scene was used. The depth of the virtual underwater world was about $20 \mathrm{~m}$.

\subsection{Result}

As a result of the study, a visual presentation with high immersive feeling was achieved in the water, and the sensor for head tracking kept the same accuracy and refresh rate as it did on dry land. Therefore, it has been demonstrated that this system operates normally at a depth of about $4 \mathrm{~m}$.

In the questionnaire that we distributed after the experiment, all participants commented that they felt like they were "in deep water even though it should feel like shallow water." This indicates that our system has the potential to provide underwater experiences of various depths despite being used in a pool. 

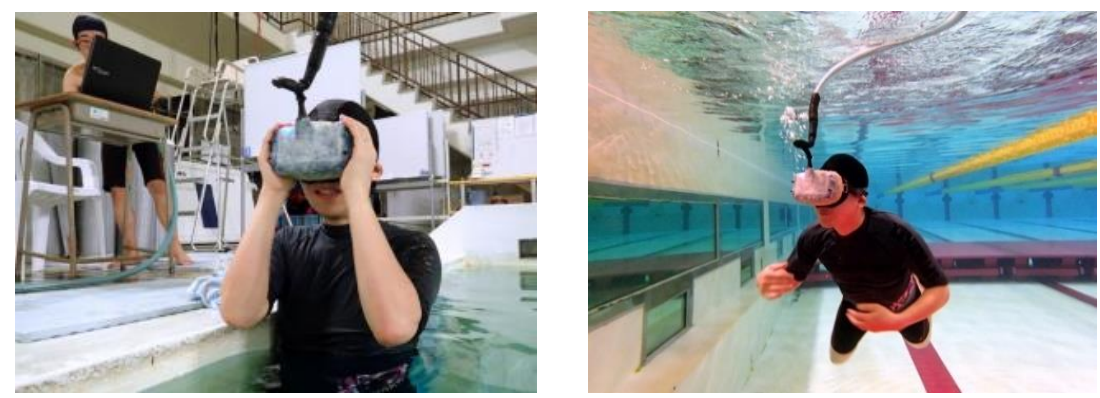

Fig. 4. Diving while wearing the UHMD.

\section{$5 \quad$ Future Work}

\subsection{Intuitive Operation}

Virtual movement in the current system is not intuitive because it uses joysticks, the trigger, and buttons. To achieve a more intuitive movement, it is necessary to sense the movement of the body. There are two ways to achieve this. One is to use an external sensor system such as a camera (Fig. 5, left). The other one is to use an internal sensor such as a bend sensor (Fig. 5, right). Currently, we are working toward achieving motion capture underwater using a stereo camera. We also track the walls and bottom of the pool using edge detection and markers to avoid allowing the user to bump against them.

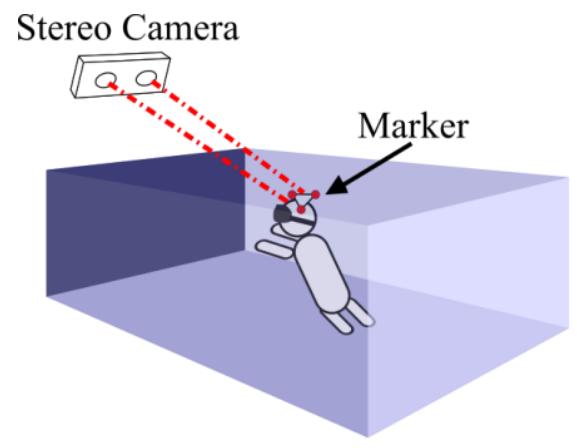

External Sensor

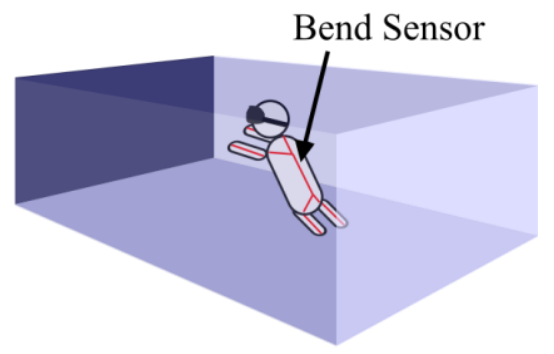

Internal Sensor

Fig. 5. Schematic of movement capture methods

\subsection{Quality of the Content}

For this study, we created content that would not fall below 75 fps. However, the reality was decreased somewhat. To achieve both high content quality and refresh rate, it is necessary to find ways to reduce the processing load such as adjusting the mesh of a 
3D model, canceling undisplayed part rendering, or introducing single-pass stereo rendering.

\section{Conclusion}

In this paper, we proposed a virtual scuba diving system using a UHMD and attempted to realize an arbitrary underwater environment experience in familiar underwater areas such as a pool. Our aim is to achieve the overwhelmingly immersive feeling obtained with a dedicated HMD and enable the user to move freely. We developed a prototype of our system and created underwater content. The results of the pilot study confirmed that our system works well in water and has the potential to provide underwater experiences of various depths despite being in a pool. We will continue to improve image quality and pursue further immersive reality by improving the content so that it can be linked to user movement.

\section{References}

1. XL Catlin Seaview Survey, http://catlinseaviewsurvey.com, 2017/4/24

2. Sumsung Shark Dive VR, https://www.sammobile.com/2016/04/02/samsung-uploads-360degree-shark-dive-video-to-youtube, 2017/4/24

3. Wevr theBlu, http://blog.wevr.com/acclaimed-vr-series-theblu-out-on-transport-oculustouch-896, 2017/4/24

4. Dhruv, J., Misha, S., Jingru, G., Rodrigo, M., Raymond, W., Justin, C., Chris, S.: Amphibian, Immersive Terrestrial Scuba Diving Using Virtual Reality, Proceedings of the 2016 CHI Conference Extended Abstracts on Human Factors in Computing Systems Pages 1563-1569,(2016)

5. Abdelkader, B., Christophe, D., Samir, O., Samir, B., Alain, D.: Augmented reality for underwater activities with the use of the DOLPHYN. 10th IEEE International Conference on Networking, Sensing and Control (ICNSC 2013), Apr 2013, Evry, France. pp.409-412. (2013)

6. Shogo,Y., Xinlei, Z, Takashi, M,. Jun, R., AquaCAVE: An Underwater Immersive Projection System for Enhancing the Swimming Experience, ICAT-EGVE2016,

7. AquaCAVE: Augmented Swimming Environment with Immersive Surround-Screen Virtual Reality, https://lab.rekimoto.org/projects/aquacave, 2017/4/24

8. Nautilus VR Virtual Reality Underwater, https://www.kickstarter.com/ projects/remotte/project-nautilus-vr-virtual-reality-underwater, 2017/4/24

9. Wenlong, Z., Chek Tien, T., Tim, C.: A safe low-cost HMD for underwater VR experiences. SA '16 SIGGRAPH ASIA 2016 Mobile Graphics and Interactive Applications Article No. 12(2016)

10. Experience Weightless VR With This Waterproof Headset, https://vrscout.com/news/experience-weightless-vr-waterproof-headset, 2017/4/24

11. Oculus Best Practices, https://static.oculus.com/documentation/pdfs/intro-vr/latest/bp.pdf, $2017 / 4 / 24$ 